Sensors and Actuators B 156 (2011) 162-168

\title{
An Electrochemical Sensor Based on Carboxymethylated Dextran Modified Gold Surface for Ochratoxin A Analysis
}

Meike Heurich, Mohamad Kamal Abdul Kadir and Ibtisam E. Tothill*

Cranfield University, Cranfield Health, Cranfield, Bedfordshire, MK43 0AL, England, UK.

Corresponding author: Tel.: +44 (0) 7500766487

E-mail: i.tothill@cranfield.ac.uk, 


\section{Abstract}

A disposable electrochemical immunosensor method was developed for ochratoxin A analysis to be applied for wine samples by using a screen-printed gold working electrode with carbon counter and silver/silver chloride pseudo-reference electrode. An indirect competitive enzyme-linked immunosorbent assay (ELISA) format was constructed by immobilising ochratoxin A conjugate using passive adsorption or covalent immobilisation via amine coupling to a carboxymethylated dextran (CMD) hydrogel on the gold working electrode. Electrochemical detection was performed using 3,3',5,5'- tetramethylbenzidine dihyrochloride (TMB) and hydrogen peroxide with horse radish peroxidase (HRP) as the enzyme label. Chronoamperometry at -150 $\mathrm{mV}$ vs. onboard screen-printed $\mathrm{Ag}-\mathrm{AgCl}$ pseudo-reference electrode was then used to detect the generated signal. The performance of the assay and the sensor was optimised and characterised in pure buffer conditions before applying to wine samples. The resulting immunosensor for ochratoxin $\mathrm{A}$ in buffer achieved a limit of detection of 0.5 $\mu \mathrm{g} \mathrm{L}{ }^{-1}$ with a linear dynamic detection range of $0.1-10 \mu \mathrm{g} \mathrm{L}^{-1}$ for passive adsorption of the toxin conjugate. While for covalent immobilisation through CMD-modified gold electrode, a limit of detection of $0.05 \mu \mathrm{g} \mathrm{L}^{-1}$ was achieved with a linear dynamic detection range of $0.01 \mu \mathrm{g} \mathrm{L}^{-1}$ to $100 \mu \mathrm{g} \mathrm{L} \mathrm{L}^{-1}$. The CMD-modified gold immunosensor was then evaluated in spiked and affinity purified wine samples achieving a detection limit comparable to buffer solutions $\left(0.05 \mu \mathrm{g} \mathrm{L}{ }^{-1}\right)$.

Keywords: Ochratoxin A, mycotoxins, screen-printed gold electrode, carboxymethylated dextran, immunosensor, wine samples. 


\section{Introduction}

Ochratoxin A is a mycotoxin produced by fungi such as Aspergillus and Penicillium [1] that grow on grapes and contaminate the wine and therefore pose a serious health risk for the consumer. Mycotoxins are produced as secondary metabolites by the fungi with diverse chemical structures and physical properties, and hence exhibit various biological effects on mammalian systems. They can be genotoxic, teratogenic, mutagenic, embryogenic, oestrogenic or immunosuppressive [2-6]. Ochratoxin A (OTA), 7-(L- $\beta$ - phenylalanylcarbonyl)-carboxyl-5-chloro-8-hydroxy-3,4-dihydro-3R methylisocumarin, has been considered by the International Agency for Research on Cancer to be possibly carcinogenic (group 2B) for humans [3].

Ochratoxin A can be found in grapes, grape juice, and wine [7] as well as foods from (sub)-tropical origin like maize, coffee beans, cocoa or soy beans [4]. Levels of ochratoxin A contamination sampled in Europe ranged in wine 0.01-7.0 $\mu \mathrm{g} \mathrm{L}^{-1}$. As a result of ochratoxin A contamination of foodstuff and beverages, the toxin was found at levels greater than $0.1 \mu \mathrm{g} \mathrm{kg}^{-1}$ in more than $90 \%$ of human blood samples from central European origin [6]. Increased awareness of the potential risk of ochratoxin A has led the European Commission (EC regulation 123/2005) to set a permissible limit of ochratoxin $\mathrm{A}$ in wine and grape-containing beverages to $2 \mu \mathrm{g} \mathrm{L}^{-1}$. Ochratoxin $\mathrm{A}$ contamination is not only a matter of concern for consumer's health, but it is also one of economic importance. Since regular exposure to ochratoxin A can occur through grapes products and wine consumption, a more rapid and sensitive analytical methods are required that can quantify ochratoxin A effectively.

Methods used as standard techniques to monitor ochratoxin A contamination include thin-layer chromatography (TLC) and high-performance liquid chromatography (HPLC) [8-9]. Chromatography-based techniques however, are laboratory based and often require highly processed samples (in relation to clean-up) to achieve sensitive detection limits. Therefore, immunochemical methods have become more popular in recent years as methods of analysis, with many publications in the literature reporting on their use for mycotoxins analysis [10-12]. 
Electrochemical sensors have been proven to be sensitive analytical tools allowing rapid and decentralised analysis for on-site sampling [13]. Therefore, immunosensors have gained considerable interest in the field of clinical diagnosis, and more recently in environmental and food analysis [14-15]. The use of advanced sensor fabrication technologies in the manufacture of disposable sensors such as screen-printed sensors allowed the mass production of reproducible and sensitive transducer devices [16-17]. These types of sensors are also cost-effective and circumvent common samples analysis problems resulting from carry-over effects or surface fouling. Sensors based on screenprinting technology are increasingly being developed for food safety and quality monitoring [18-20].

Screen-printed working electrodes are usually produced using carbon ink; however, more recently noble metals such as gold $(\mathrm{Au})$ and Platinum $(\mathrm{Pt})$ inks have been used [20-22]. Gold as a transducer material has been known for its stability, very good electrical conductivity, chemical inertness, corrosion resistance and also be easily chemically modified for covalent molecular immobilisation. Passive adsorption is one of the simplest and most frequently used immobilisation techniques where binding takes place based mainly on weak non -covalent bindings. However, random protein orientation can lead to the obstruction of functional binding sites and results in the loss of affinity or activity. Thus covalent attachment of a protein layer on a chemicallyfunctionalized gold surface appears more advantageous as it allows a more stable layer with the correct orientation to be immobilised. The correct immobilization strategy influences sensitivity and specificity of the immunoassay as density of immobilised protein can be better controlled and non-specific adsorption may be decreased [23]. Functional modification of gold electrodes is usually achieved by chemisorptions of thiol compounds or modification with polysaccharides such as dextran and its derivatives [24]. Carboxymethylated dextran modified gold chips have been commercially exploited by Biacore ${ }^{\mathrm{TM}}$ for their surface plasmon resonance sensor chips [25-26]. More recently it has been investigated in the development of other types of sensor chips [27-29]. There is a great need to develop sensitive and rapid detection methods for ochratoxin A analysis that exceed traditional ones regarding mainly costand time-effectiveness. In recent years, several techniques for ochratoxin A determination have emerged (30), based on different sensing receptor and transducers (31-34) with electrochemical immunosensors being the most widely reported (35 - 38). 
Common problems reported include the poor reproducibility of some of the assay on the screen-printed electrodes and also high nonspecific binding.

In this paper we report on the development of an electrochemical immunosensor for ochratoxin A detection using gold screen-printed working electrodes rather than carbon electrode. This was to enable chemical modification of the sensor surface and the application of different immobilisation strategies to enable the production of a more reproducible sensor device and to enhance the sensitivity and stability of the sensor surface and reduce nonspecific binding as the gold electrode is more inert than the traditional screen-printed carbon electrodes. Passive adsorption and covalent immobilisation using carboxymethylated dextran modified gold electrodes via amine coupling chemistry were investigated for the immobilisation of ochratoxin A conjugate onto the working electrode surface. An indirect competitive ELISA format was then developed using a heterogeneous assay procedure. Chronoamperometry was applied as the signal detection method with $\mathrm{TMB} / \mathrm{H}_{2} \mathrm{O}_{2}$ as the mediator- substrate system catalysed by the enzyme label (HRP). The immunoesensor was then investigated with regards to interference from wine matrix.

\section{Experimental}

\subsection{Reagents}

Polystyrene micro titre plates were purchased from Nunc Brand (Roskilde, Denmark). Horseradish peroxidase-labelled secondary antibody was from Dako UK Ltd. (Ely, UK). The 3,3',5,5'-Tetramethylbenzidine (TMB) substrate solution was from Europa Bioproducts Ltd (Ely, UK) containing $2.08 \mathrm{mM} \mathrm{L}^{-1} \mathrm{TMB}$ and Hydrogen Peroxide in citric acid buffer at $\mathrm{pH}$ 3.3. Ochratoxin A-BSA conjugate and ochratoxin A, 30\% hydrogen peroxide solution, dextran (MW 10,000) and polyvinyl alcohol (PVA) and ophenylenediamine dihydrochloride (OPD) were purchased from Sigma-Aldrich Ltd. (Poole, UK). Polyclonal anti-ochratoxin A antibody was obtained from Acris Antibodies GmbH (Hiddenhausen, Germany). Di-sodium phosphate, sodium hydrogen phosphate, sodium chloride, potassium chloride, chloroacetic acid, sodium hydroxide, hydrochloric acid, sodium acetate, glycine and acetonitrile and methanol (HPLC grade) 
were Fluka brand purchased from Sigma Aldrich Ltd (Poole, UK). N-ethyl- $N$ '-(3dimethylaminopropyl)-carbodiimide (EDC), $N$-hydroxysuccinimide (NHS) and $0.1 \mathrm{M}$ ethanolamine was from Biacore AB (Uppsala, Sweden). The immunoassay test kit (Ridascreen®) was from R-Biopharm (Rhône Ltd., UK).

For screen-printing graphite ink Electrodag $423 \mathrm{SS}$, silver/silver chloride ink Electrodag 6037 SS were from Acheson Colloiden BV (Scheemda, NL). Gold ink E4464 was purchased from Ercon Inc. (West Wrexhamn, MA, USA) and the epoxybased protective coating ink Type 242-SB from ESL Europe Ltd. (Reading, UK). Melinex sheets MEL ST225 (228 mm x $305 \mathrm{~mm}, 250 \mu \mathrm{m})$ were obtained from Cadillacprinting Ltd. (Swindon, UK). The edge connector with ribbon data cable (DG41U) and a '3-copper core' (non-plated) individually screened cable and was purchased from Maplin Electronics Ltd. (Milton Keynes, UK). Wine samples were chosen from distinct origins and grape species and all purchased from local stores (Tesco, UK). The electrolyte buffer is phosphate buffered saline (100 mM), pH 7.4, containing $0.1 \mathrm{M} \mathrm{KCl}$.

\subsubsection{Safety awareness}

Due to the toxic and potential carcinogenic properties of ochratoxin A, safety precautions were applied, such as wearing gloves, protection glasses and lab coat at all times and a facial mask when handling powder ochratoxin A. The toxin was stored in a locked fridge specified for toxic reagents according to safety instructions.

\subsubsection{Fabrication of screen-printed electrodes}

The screen-printed gold electrodes (SPGE) used in this work, consisting of a gold working electrode $\left(1.3 \mathrm{~mm}^{2}\right.$ planar area), carbon counter and $\mathrm{Ag} / \mathrm{AgCl}$ reference electrode, were mass fabricated in-house by a multi-stage screen-printing process using a DEK model 248 machine (DEK, Weymouth, UK) [39]. Stainless steel screens with a screen mesh size of 200 counts per inch were used to print the electrodes. The electrodes were printed onto $250 \mu \mathrm{m}$ thick Melinex polyester sheet. Typical film thickness of screen printed sensors ranged from 10 to $50 \mu \mathrm{m}$. The print parameters were set so that the squeegee pressure was 4 psi, a carriage speed of $50 \mathrm{~mm} \mathrm{~s}^{-1}$ and a print 
gap of $2.6 \mathrm{~mm}$. At first, the conducting basal tracks were printed using graphite based ink and dried in an oven at $100{ }^{\circ} \mathrm{C}$ for 2 hours. In the second step, silver/silver chloride was printed onto one of the terminal basal tracks and dried in an oven at $100{ }^{\circ} \mathrm{C}$ for 2 hours. For screen-printed gold electrode construction, another basal track was reprinted with one deposit of gold ink at an increased carriage speed of $66 \mathrm{~mm} \mathrm{~s}^{-1}$ and then dried as above. In the last step, the basal tracks were insulated with a protective coating ink leaving a defined circular shaped area (area of $3.2 \mathrm{~mm}^{2}$ ) necessary for the electrical contact in measurements. The insulation layer was cured at $100{ }^{\circ} \mathrm{C}$ for 1 hour in order to stabilise the epoxy resin. About 100 electrodes are printed per sheet at a time; and were then cut into individual electrodes.

\subsection{Procedures}

\subsubsection{Electrochemical measurements}

Prior to use, the SPGEs were incubated at $100{ }^{\circ} \mathrm{C}$ for 30 minutes to remove any particles from the surface. Each SPGE was then cleaned with distilled water and dried under $\mathrm{N}_{2}$. The electrodes were inserted, applying a 'push-fit' action, via their carbon basal track into a 34-way edge connector with ribbon data cable. Each basal track is connected via a single pin and the copper outlets of the ribbon cable were manually soldered to crocodile clamps that were connected to a '3-copper core (non-plated) individually screened cable' leading towards the PC-controlled Autolab potentiostat / galvanostat. The detector is run by the software package type GPES 4.9 (Metrohm Autolab B.V., Utrecht, Netherlands). Up to four electrodes can be fitted into the edge connector and monitored simultaneously. Here, three electrodes were attached simultaneously for triplicate measurements. In multi-mode GPES, cyclic voltammetry or chronoamperometry was selected from the menu and parameters set as described below.

\subsubsection{Assessment of the optimal working electrode potential}

Cyclic voltammetry (CV) analysis was used to characterise the electrochemical behaviour of 3,3',5,5'-tetramethylbenzidine (TMB) with the in-house produced screenprinted gold electrodes. Detection was conducted using (TMB) and hydrogen peroxide 
$\left(\mathrm{H}_{2} \mathrm{O}_{2}\right)$ as the mediator/substrate system. TMB shows a typical two-shoulder redox peak on gold electrodes.

For the analysis, ready-made TMB solution was used. According to the manufacturer (Europa Bioproducts Ltd., Ely, UK), the TMB solution is stable at room temperature and is not sensitive to normal laboratory light. It is optimized with respect to TMB and hydrogen peroxide concentrations and yields a linear response with the concentrations of HRP usually employed in immunological assays. It also contains stabilisers.

A $20 \mu 1$ solution of TMB in electrolyte buffer $(0.1 \mathrm{M} \mathrm{KCl})$ was deposited on a bare SPGE and cyclic voltammetry (CV) was performed at a scanning range from -1 to $+1 \mathrm{~V}$ with step potential of $2.7 \mathrm{mV}$. By increasing the scan rate step wise, the increase in peak current can be related to the redox behaviour of TMB on the screen- printed gold working electrode $v s$. silver/silver chloride reference electrode printed on the same sensor platform. The optimum working electrode potential for TMB solution was selected using step amperometry. A $20 \mu \mathrm{L}$ solution of $100 \mathrm{mg} \mathrm{L}^{-1} \mathrm{TMB}$ in electrolyte buffer was deposited on a bare SPGE and the working potential increased step-wise (100 seconds per potential step). Each signal point was recorded at time 50 seconds of each step potential. The optimal working potential was selected as the potential of the highest signal (TMB and electrolyte buffer) / background (electrolyte buffer) current ratio.

\subsubsection{Indirect competitive immunoassay for ochratoxin A}

An indirect competitive immunoassay was first developed before moving the assay to the sensor surface. Assay parameters were first examined and optimised for the final assay design using a checkerboard titration assay. Different concentrations of ochratoxin A-BSA conjugate were passively immobilised $\left(0.1-50 \mathrm{mg} \mathrm{L}^{-1}\right.$ in $100 \mathrm{mM}$

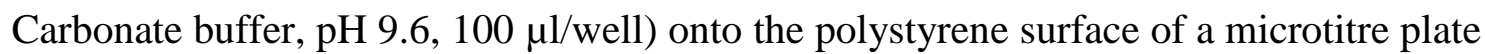
(MaxiSorb $^{\mathrm{TM}}$ ) for 16 hours at $4^{\circ} \mathrm{C}$. This was followed by washing three times $(150 \mu \mathrm{l} /$ well) using phosphate buffered saline containing Tween 20 (PBST, pH 7.4). The plates were then blocked using 1\% (w/v) of either BSA or casein in PBS (pH7.4, $100 \mu \mathrm{l} / \mathrm{well})$ and incubated at $4^{\circ} \mathrm{C}$ for 2 hours, followed by washing. Samples of ochratoxin A competes with immobilised ochratoxin A-BSA for the specific antibody (polyclonal 
antibody raised against ochratoxin A) binding sites. A dilution of 1/200 from $1 \mathrm{mg} \mathrm{ml}^{-1}$ stock solution of anti-ochratoxin A antibody solution (PBS, pH 7.4) was used (100 $\mu 1 /$ well) and incubated at $37^{\circ} \mathrm{C}$ for about 2 hours followed by washing. Finally, a dilution of $1 / 2000$ anti-rabbit-IgG-HRP was added $(100 \mu \mathrm{l} /$ well $)$ and incubated at $37^{\circ} \mathrm{C}$ for 1.5 hours. The plates were then washed as above and the substrate solution of ophenylenediamine (OPD) and $\mathrm{H}_{2} \mathrm{O}_{2}(100 \mu \mathrm{l} /$ well $)$ was then added and incubation performed at room temperature (RT) for 15 minutes before measuring the absorbance at $492 \mathrm{~nm}$, using a plate reader. The resulting signal is inversely proportional to sample ochratoxin A concentration. Optimal analyte concentrations were established by titration assays.

\subsubsection{Amperometric immunosensor for ochratoxin $A$}

The optimised indirect competitive immunoassay format was then moved to the surface of the electrochemical immunosensor. The immunosensor was optimised with respect to coating concentration of adsorbed ochratoxin A-BSA (range $0.5-100 \mathrm{mg} \mathrm{L}^{-1}$ in 0.1 M PBS, pH 7.4) and ochratoxin A- antibody (range 1-100 $\mathrm{mg} \mathrm{L}^{-1}$ ) and $\mathrm{HRP} / \mathrm{TMB} / \mathrm{H}_{2} \mathrm{O}_{2}$ loading. The final protocol resumed with the drop deposition of $20 \mu 1\left(10 \mathrm{mg} \mathrm{L}^{-1}\right)$ ochratoxin A-BSA conjugate in 0.1 M PBS, pH 7.4 onto the surface of the working gold electrode and incubation for 2 hours at $37{ }^{\circ} \mathrm{C}$. The electrodes were then washed with phosphate buffered saline containing $0.05 \%$ Tween 20 (PBST) followed by PBS. The electrodes were blocked by dipping the electrodes into 1\% PVA solution for 1 hour. Specific ochratoxin A antibody $\left(20 \mu 1,10 \mathrm{mg} \mathrm{L}^{-1}\right.$ in $0.1 \mathrm{M}$ PBS, pH 7.4) was added to serial dilutions of $10 \mu \mathrm{l}$ ochratoxin A, mixed briefly and deposited onto the gold working electrode and incubated for 2 hours at $37{ }^{\circ} \mathrm{C}$. The electrodes were then washed as above and horseradish peroxidase (HRP)-labelled secondary antibody ( 0.5 $\mathrm{mg} \mathrm{L}^{-1}$ in 0.1 M PBS, pH 7.4) was added and incubated for 1 hour. All incubations were performed at $37{ }^{\circ} \mathrm{C}$ in a humidity chamber. The electrodes were washed with PBST, PBS and the amount of bound ochratoxin A was then determined using chronoamperometry at a set potential of $-150 \mathrm{mV}$. A $20 \mu \mathrm{l}$ electrolyte solution (PBS, $\mathrm{pH} 7.4$ containing $0.1 \mathrm{M} \mathrm{KCl}$ ) was added onto the electrode surface at time zero where the current resulting from electrolyte buffer is monitored as baseline for 50 seconds. The TMB/ $\mathrm{H}_{2} \mathrm{O}_{2}$ solution $(50 \mu \mathrm{l})$ is then added onto the electrode and the current-time 
response is monitored for another 250 seconds (total measurement time per electrode is 300 seconds after the addition of the substrate on the electrode surface). The baseline current was subtracted from the signal current when calculating the final signal. Measurements were performed in triplicates.

\subsubsection{Construction of CMD modified electrodes}

Covalent immobilisation of ochratoxin A-BSA and subsequent blocking with ethanolamine has been used to stabilise ochratoxin A-BSA in a hydrogel matrix and reduce non-specific binding of the detecting antibody to the sensor surface. Carboxymethylated dextran (CMD) was prepared according to the procedure reported by Surugiu et al., [40]. In brief, a volume of $1 \mathrm{ml} 40 \mathrm{mg} \mathrm{ml}^{-1}$ dextran was added to a solution consisting of $1 \mathrm{M}$ chloroacetic acid in $3 \mathrm{M} \mathrm{NaOH}$. The mixture was allowed to react while stirring for 2 hours at room temperature. The reaction was stopped by adding $4 \mathrm{mg} \mathrm{NaH}_{2} \mathrm{PO}_{4}$ per $\mathrm{ml}$ of dextran solution and the $\mathrm{pH}$ was adjusted to neutral with $\mathrm{HCl}$ solution. The excess of reactants was removed by dialysis towards $0.1 \mathrm{M}$ PBS, pH 7.4 at room temperature for 24 hours.

The gold working electrode was modified using $3 \mu$ l of carboxymethylated dextran (CMD) solution per gold working electrode and stored under nitrogen at room temperature. The CMD-modified gold working electrode was then activated by liquid/spot deposition using $5 \mu \mathrm{l}$ of a 1:2 mixture of $0.05 \mathrm{M}$ NHS and 0.2 M EDC. Then, a solution of $20 \mu 110 \mathrm{mg} \mathrm{L}^{-1}$ ochratoxin A-BSA was added and the electrodes left to incubate for 2 hours at $37{ }^{\circ} \mathrm{C}$. The sensors were washed using PBST/PBS. Remaining activated binding sites on the carboxymethylated dextran surface were blocked by depositing ethanolamine ( $2.5 \mu 10.1 \mathrm{M}$ ethanolamine, $\mathrm{pH} 8.5)$ onto the gold working electrode and incubating at $37{ }^{\circ} \mathrm{C}$ for 30 minutes. Another blocking step of $1 \%$ PVA was introduced covering the entire electrode area for 30 minutes. After washing, $20 \mu \mathrm{l}$ of $10 \mathrm{mg} \mathrm{mL}^{-1}$ anti-ochratoxin $\mathrm{A}$ was premixed with serial ochratoxin $\mathrm{A}$ solutions (0- $1000 \mu \mathrm{g} \mathrm{L}^{-1}$, as described earlier), before deposited onto the electrode surfaces (three separate electrodes for every concentration of ochratoxin A allows for triple measurements). The sensors were incubated subsequent steps using the secondary antibody and detection with $\mathrm{TMB} / \mathrm{H}_{2} \mathrm{O}_{2}$ was performed as described above. The limit of detection (LOD) was calculated according to Currie (1997) [41] 


\subsubsection{CMD-sensor response in spiked and extracted wine samples}

The developed CMD-sensor was then examined for its performance using spiked and affinity purified wine samples and compared to buffer samples analysis. For this experiment Ochraprep ${ }^{\circledR}$ from R-Biopham AG (Darmstadt, Germany) immunoaffinity column was used to extract and purify ochratoxin A from the wine samples. Therefore, wine samples were prepared and extracted following the Ochraprep ${ }^{\circledR}$ procedure. In summary, spiked wine samples with ochratoxin A $\left(0-1000 \mu \mathrm{g} \mathrm{L}^{-1}\right)$ were degassed using ultrasonic bath for 30 minutes and then the $\mathrm{pH}$ was adjusted to 7.2 using a $2 \mathrm{M}$ sodium hydroxide. Wine samples $(1.5 \mathrm{ml})$ were then passed through the immunoaffinity column at a flow rate of $2-3 \mathrm{ml} /$ minute. The column was then washed by passing $2 \mathrm{ml}$ of PBS and dried by passing air through the column. Bound ochratoxin A was then eluted using $1.5 \mathrm{ml}$ of desorption solution (acetic acid: methanol 2:98), using back flushing for 3 times with the same solution to ensure complete elution of Ochratoxin A. The column was then flushed with air to collect the eluate. A $1.5 \mathrm{ml}$ of distilled water was then flushed through the column and collected with the sample vial. The eluate was then diluted 1:10 with buffer before the analyses.

The analysis method using the CMD-sensor was modified slightly from the previous procedure by premixing a $20 \mu \mathrm{l}$ of $10 \mathrm{mg} \mathrm{mL}^{-1}$ anti-ochratoxin A with the extracted samples $(10 \mu \mathrm{l})$ and then incubate for 30 minute before deposition on the surface of the sensor and incubating for 1 hour at $37^{\circ} \mathrm{C}$. The sensor was then washed twice with PBST and once with PBS and a $20 \mu \mathrm{l}$ of anti-rabbit antibody - HRP $\left(0.5 \mathrm{mg} \mathrm{L}^{-1}\right)$ was then added and incubated for 1 hour at $37^{\circ} \mathrm{C}$ and washed as before. For the detection, a $5 \mathrm{mM} \mathrm{TMB} / 0.075 \% \mathrm{H}_{2} \mathrm{O}_{2}$ was placed onto the surface and the current measured using Chronoamperometry at a set potential $-150 \mathrm{mV}$.

\section{Results and discussion}

The electrochemical immunosensor system developed in this work for ochratoxin A detection was based on an indirect competitive immunoassay format with HRP used as the enzyme label and $\mathrm{TMB} / \mathrm{H}_{2} \mathrm{O}_{2}$ as the substrate/mediator system as illustrated in 
Figure 1. The higher the ochratoxin A in the sample, the lower the signal achieved from the electrochemical immunosensor.

\subsection{Characterisation of TMB on the gold working electrode}

TMB showed a typical redox characteristics on the in-house prepared screen- printed gold electrode which confirmed that the produced gold disposable sensor can be used for the analysis using TMB as the redox mediator/substrate solution. The dependence of peak current $\left(i_{\mathrm{p}}\right)$ with scan rate $(v)$ for the redox reaction of TMB was shown on the screen-printed gold electrode as a gradual increase in the peak current in relation to the increase in scan rate. Figure 2 shows the cyclic voltammograms at increasing scan rates displaying the characteristic TMB double shoulder on the positive scan, which are the result from the two 1-electron oxidation steps of TMB. The negative scan is illustrating a 2-electron reduction step. This indicates that the electrochemical reaction is a quasireversible. The oxidation/reduction peaks were more defined when lower scan rates were used. Hence the TMB peaks were found to be most profound at scan rates in the range of $25-75 \mathrm{mV} \mathrm{s}^{-1}$ and a scan rate of $50 \mathrm{mV} \mathrm{s}^{-1}$ was selected for cyclic voltammetry analysis. TMB also shows the same characteristic redox peaks on CMD-modified screen printed gold electrodes (data not shown).

The optimum working electrode potential for TMB using this sensor configuration with the gold as a working electrode was selected using step amperometry. The signal current increased significantly at negative step potentials. Within the positive step potential range of $>0 \mathrm{~V}$ to $+400 \mathrm{mV}$ the relative current change was less with increasing step potential. The highest signal to background current ratio was observed at -200 to $+200 \mathrm{mV}$ where the current arising from electrolyte buffer (PBS, $0.1 \mathrm{M} \mathrm{KCl}$, $\mathrm{pH}$ 7.4) was near zero. The low background current is optimal for enzyme activity determination when a small amount of catalysis product $\left(\mathrm{TMB}_{\mathrm{ox}}\right)$ needs to be measured in the presence of high concentrations of substrate [42, 43]. A working potential of -150 $\mathrm{mV}$ was chosen for this sensor for chronoamperometric measurements. Electrochemical interferences arising from polyphenols in wine samples should be negligible at the selected negative working potential used in this investigation [44]. 


\subsection{Indirect competitive immunoassay for ochratoxin A}

Initially, an indirect immunoassay format was developed on polystyrene solid phase supports (microtitre plates) prior to moving the assay to the sensor surface. The competitive immunoassay promotes competition of ochratoxin A, for anti-ochratoxin A-antibody binding sites with immobilized ochratoxin A-BSA. The optimised assay used ochratoxin A-BSA (30 mg L $\mathrm{m}^{-1}, 100 \mu \mathrm{l} /$ well), as the coating surface and 1\% (w/v) casein as the blocking solution $(100 \mu \mathrm{l} /$ well $)$. Detection was carried out using a HRPlabelled secondary antibody and $\mathrm{OPD} / \mathrm{H}_{2} \mathrm{O}_{2}$ as mediator solution, measuring the absorbance at $492 \mathrm{~nm}$. The microtitre plate ELISA assay showed a detection limit (LOD) of $1 \mu \mathrm{g} \mathrm{L} \mathrm{L}^{-1}$ ochratoxin A in phosphate buffer, $\mathrm{pH} 7.4$, with a dynamic range of $1-1000 \mu \mathrm{g} \mathrm{l}^{-1}$ and a linear $r^{2}$ value of 0.99 (Figure 3).

In comparison, published detection limits of immunoassay based test kits range from $0.1-3 \mu \mathrm{g} \mathrm{L}^{-1}$ ochratoxin $\mathrm{A}$ in food samples. The test kit from Ridascreen ${ }^{\mathrm{TM}}$ that was also used in this work for comparison states a detection limit of $0.025-0.625 \mu \mathrm{g} \mathrm{L}^{-1}$. The indirect assay developed in this work showed that an LOD of $1 \mu \mathrm{g} \mathrm{L}{ }^{-1}$ can be achieved and therefore places the hereby developed assay within the detection range achieved by commercial tests.

\subsection{Amperometric immunosensor for ochratoxin A}

The assay setup showed sufficient sensitivity to be transferred to the surface of the screen-printed gold electrode sensor using passive adsorption of ochratoxin A-BSA. First the immunosensor was optimised with respect to reagents concentrations, operating $\mathrm{pH}$ and drop deposition volume as described in the methods sections. Optimal signals were achieved when using ochratoxin A-BSA conjugate $(20 \mu 1$ /electrode surface, $10 \mathrm{mg} \mathrm{L}^{-1}$ in $0.1 \mathrm{M}$ PBS, pH 7.4), ochratoxin A- antibody (20 $\mu$ l /electrode surface, $10 \mathrm{mg} \mathrm{L}^{-1}$ in $0.1 \mathrm{M}$ PBS, pH 7.4) and horseradish peroxidase (HRP)-labelled secondary antibody $\left(0.5 \mathrm{mg} \mathrm{L^{-1 }}\right.$ in $\left.0.1 \mathrm{M} \mathrm{PBS}, \mathrm{pH} 7.4\right)$. By using an indirect competitive immunoassay format allows for the pre-incubation of the detecting antibody with the ochratoxin A in buffer sample. After the competition step on the 
electrode surface, unbound ochratoxin A is washed off, thus allowing for specific detection of the surface bound detecting antibody by the secondary antibody.

Applying the optimised reagents and established sensor conditions, a standard curve was established for ochratoxin A on the SPGE sensor using passive adsorption (Figure 4). Non-covalent immobilisation allows easy adsorption of biomolecules on the gold surface as a result of hydrophobic and thiol-gold interactions [45]. Upon TMB / $\mathrm{H}_{2} \mathrm{O}_{2}$ addition, the change in reduction current was observed over time for different ochratoxin A standard concentrations. A steady state current is observed after about 100 seconds past TMB addition. The change in current is inversely proportional to the ochratoxin A concentration. Figure 4a, shows a chronoamperometric measurement at $150 \mathrm{mV}$ vs. $\mathrm{Ag} / \mathrm{AgCl}$ for different concentrations of ochratoxin A. The linear range (Figure $4 \mathrm{~b}$ ) shows the range from $0.1-10 \mu \mathrm{g} \mathrm{L}^{-1}$ with a Liner $r^{2}$ value of 0.99 , which covers the standard EU permissible concentration of $2 \mu \mathrm{g} \mathrm{L}^{-1}$. A detection limit (LOD) of $0.5 \mu \mathrm{g} \mathrm{L}^{-1}$ was achieved with a standard deviation of $6 \%$ resulted from using the sensor. The results show nearly a ten fold increase in sensitivity as compared to the developed microtitre plate assay, which is a result of the more sensitive amperometric detection method applied. The developed sensor at the current setting compares to the detection range achieved by commercial immunochemical test kits. Furthermore, the immunosensor meets the sensitivity requirements set by the European Commission (EC regulation 123/2005).

\subsection{Sensor optimisation using CMD modified electrodes}

The sensitivity of the immunosensor device was further improved for ochratoxin A analysis. Sensitivity was optimised by covalent immobilisation of the ochratoxin ABSA-conjugate using amine coupling to a carboxymethylated dextran (CMD) modified gold working electrode. This is to increase the immobilisation capacity on the sensor surface and enhance the sensitivity of the sensor. CMD surface modification is presumed to increase stability of the active surface and decrease nonspecific binding thus reduce interferences especially from matrix effect. The electrochemical characteristics of carboxymethylated dextran were initially characterised using cyclic voltammetry on a bare SPGE. No significant oxidation or reduction peaks were monitored for $\mathrm{CMD}$ on $\mathrm{SPGE}$ vs. onboard $\mathrm{Ag} / \mathrm{AgCl}$ reference electrode (data not 
shown). The catalytic current did not decrease as opposed to that reported by Pallarola et al., [28], who observed a decrease in the catalytic current with CMD modified gold electrodes, suggesting that the CMD may hinder the access of the redox couple to the electrode surface. Our achieved results are mainly due to the type of the gold ink used in the fabrication of the screen-printed sensors and the roughness of the final electrode surface used in our work. Figure 5, illustrates the calibration curve for ochratoxin A standards when applying the CMD-modified SPGE. The plot shows linearity in the range from $0.01-100 \mu \mathrm{g} \mathrm{L}^{-1}$ with a detection limit (LOD) of $0.05 \mu \mathrm{g} \mathrm{\textrm {L } ^ { - 1 }}$ and a standard deviation in the range of $8 \%$.

The CMD modified immunosensor developed here was $\sim 10$ fold more sensitive for ochratoxin A detection and has a better detection range than the immunosensor constructed using passive adsorption of ochratoxin A-BSA. This is due to the increase in the immobilisation capacity on the sensor surface with lower steering hindrance effect due to the CMD-modified surface. Non specific binding can also be reduced due to better coverage and blocking of the gold electrode surface using this immobilisation strategy. The CMD-modified gold immunosensor is more sensitive than standard immunochemical test kits and undercuts the permissible limit of ochratoxin A in wine manifold. This indicates that this sensor can be used to detect ochratoxin A at concentrations around the permissible EU limit of detection $\left(2 \mu \mathrm{g} \mathrm{L}^{-1}\right)$. The production of this disposable screen- printed electrodes and the modification of the sensor surface with CMD and the ELISA reagents is both time-and cost-effective. The electrochemical immunosensor described in this work appears suitable for ochratoxin A analysis in real wine samples.

\subsection{Analysis of ochratoxin A in spiked Wine samples}

The developed screen-printed immunosensor based on covalent immobilisation showed a high sensitivity and reproducibility for ochratoxin A detection in buffer solutions. The sensitivity and reproducibility of the sensor was then investigated in spiked wine sample. 
In order to demonstrate that the immunosensor is able to accurately detect ochratoxin A in wine samples, and that the method developed is able to analyse the samples accurately, wine samples were spiked with different concentrations of ochratoxin A first and then extracted using immunoaffinity column and analysed using the immunosensor. Figure 6, show the results achieved from spiked and affinity purified wine samples and comparison with buffer samples. The data show that highly comparable results can be achieved between buffer and wine spiked samples when the samples of wine are extracted and purified using affinity columns. The dynamic range for the sensor response in spiked wine samples was found to be 0.01-100 $\mu \mathrm{g} \mathrm{L}^{-1}$. LOD $=0.05-0.06 \mu \mathrm{g} \mathrm{L}^{-1}$, Coefficient of variation $=7.3 \%$ for wine samples. The results also show the high capability of the developed sensor in achieving high sensitivity and reproducibility for wine samples analysis.

In this work our aim was to develop a sensor method for ochratoxin A analysis that can give sensitive and accurate results in wine samples. From the results achieved here we depict a sensitive procedure for the analysis of ochratoxin A in real samples such as wine. The sensor showed very good and comparative sensitivity when compared to other electrochemical immunosensors such as that reported by Alarcon et al (35) (0.06 $\mu \mathrm{g} \mathrm{L}^{-1}$ ), but showed superior sensitivity than that reported by Prieto-Simón et al (36) who developed the sensor for wine analysis $\left(0.7 \mu \mathrm{g} \mathrm{L}^{-1}\right)$. Other researchers reported the use of other receptors and also other sensors formats which seem much more complicated than the reported sensor developed here but in some cases report similar or higher detection limits $(31,37)$. The method developed in this work is also generic and can be applied to the analysis of ochratoxin in other food matrix.

\section{Conclusions}

A cost-effective and sensitive immunosensor for ochratoxin A was fabricated using screen-printing technology as the sensor platform. The sensor incorporated a CMDmodified gold working electrode. The developed immunosensor for ochratoxin A resulted in an improved detection limit by 10 fold $\left(0.05 \mu \mathrm{g} \mathrm{L}^{-1}\right)$ applying gold electrodes modified with CMD. The level of detection using this sensor is equivalent to the lowest level of wine contamination with ochratoxin A in Europe $\left(0.01-7 \mu \mathrm{g} \mathrm{L}^{-1}\right)$ and outreaches the permissible limit of ochratoxin A in wine and grape containing 
drinks set by the European Commission $\left(2 \mu \mathrm{g} \mathrm{L} \mathrm{L}^{-1}\right)$. The developed electrochemical immunosensor using carboxymethylated dextran has shown to be a useful device for screening of wine samples. Accurate results were achieved when samples were extracted and purified using immunoaffinity columns (SPE) before analysis using the developed sensors.

\section{Acknowledgements}

The authors thank the European Commission for supporting this work (FP6-IST1508774-IP “ GOODFOOD: Food safety and quality with Microsystems Technology”) 


\section{References}

1. Bhatnagar D, Ehrlich K.C., Chang P.K. (2001) In: Encyclopedia of Life Sciences: (online resource), John Wiley.

2. Smith JE, Henderson RS (1991) In: Food Chemical Safety. Vol. 1-Contaminants, 2001, Ch.11, ed. D.H. Watson: Woodhead Publishing.

3. International Agency for Research on Cancer (IARC) (1993) List of IARC group 2b carcinogens: Ochratoxin A. Lyon, France.

4. Adams MR, Moss MO (1997) Food Microbiology, The Royal Society of Chemistry.

5. WHO (World Health Organisation) (1996) Ochratoxin A - Toxicological Evaluation of Certain Food Additives and Contaminants. WHO Food Additives Ser. 35.

6. Petzinger E, Weidenbach A, (2002) Mycotoxins in the food chain, Livestock Production Science 76: 245.

7. Zimmerli B, Dick R (1996) Food Additives Contamination 13: 655.

8. Lin L (1998) Journal of Chromatography A. 15: 830.

9. Visconti A, Pascale M, Centonze G (1999) Journal of Chromatography A. 864: 89.

10 Tothill IE (2003) $1^{\text {st }}$ ed. Rapid and on-Line Instrumentation for Food Quality Assurance: Woodhead Publishing Limited.

11. Rodriguez Velasco ML, Calonge Delso M.M, Ordonez Escudero D (2003) Food Additives and Contaminants 20: 276.

12. Logrieco A, Arrigan D W M, Brengel-Pesce K, Siciliano P, Tothill IE (2005) Food Additives and Contaminants 22:335.

13. Tothill IE, Turner APF (2003) In: Encyclopaedia of Food Sciences and Nutrition (Second Edition), Benjamin Caballero (Editor in Chief), Luiz Trugo and Paul Finglas (editors), Academic Press. 
14. Hart JP, Crew A, Crouch E, Honeychurch KC, Pemberton RM (2004) Analytical Letters 37: 789.

15. Parker CO, Tothill IE (2009) Biosensors \& Bioelectronics 24: 2452.

16. Crew A, Alford C, Cowell DCC, Hart JP (2007) Electrochimica Acta 52: 5232.

17. Kadara RO, Tothill IE (2008) Analytical Chimica Acta, 623:76.

18. Susmel S, Guilbault GG, O'Sullivan CK (2003) Biosensors \& Bioelectronics 18: 881 .

19. Masawat P, Slater JM (2007) Sensors and Actuators B: Chemical 124: 127.

20. Salam F, Tothill IE (2009) Biosensors and Bioelectronics 24: 2630.

21. Laschi S, Palchetti I, Mascini M (2006) Sensors and Actuators B: Chemical 114: 460.

22. Balkenhohl T, Lisdat F (2007) Analytica Chimica Acta 597:50.

23. Bilitewski U (2006) Analytica Chimica Acta 568(1-2):232-47.

24. De Sousa Delgado A, Leonard M, Dellacherie E (2001) Langmuir 17: 4386.

25. Lofas S, Johnsson B J (1990) Chem. Soc. Chem. Commun 21:1526.

26. Johnsson B, Lofas S, Lindqvist G (1991) Anal. Biochem. 198: 268.

27. Priano G, Pallarola D, Battaglini F (2007) Analytical Biochemistry 362:108.

28. Pallarola D, Domenianni L, Priano G, Battaglini F (2007) Electroanalysis 19: 690.

29. Baldrich E, Laczka O, Del Campo FJ, Muñoz FX (2008) Journal of Immunological Methods 336: 203.

30. Tothill IE (2011) In: Determining Mycotoxins and Mycotoxigenic Fungi in Food and Feed (edit,: Prof. Dr. Sarah De Saeger), Woodhead Publishing Limited. ISBN; 978$1-85573-728-0$.

31. Barthelmebs L, Jonca J, Hayat A, Prieto-Simon B, Marty J-L (2011). Food Control, 22, 737-743. 
32. Kuang H, Chen, Xu D, Xu L, Zhu Y, Liu L, Chu H, Peng C, Xu C, Zhu S (2011) Biosensors and Bioelectronics, 26, 710-716.

33. Yuan J, Deng D, Lauren D R, Aguilar M-I, Wu Y (2009) Analytica Chimica Acta, $656,63-71$.

34. Sauceda-Friebe J C, Karsunke X YZ, Vazac S, Biselli S, Niessner R, Knopp D ( 2011) Analytica Chimica Acta, 689, 234-242.

35. Alarcón , S.H.; Palleschi, G.; Compagnone, D.; Pascale, M.; Visconti, A.; BarnaVetró, I. (2006) Talanta, 69: 1031.

36 Prieto-Sim`on B., Camp`as M., Marty J-L., Noguer T. (2008) Biosensors and Bioelectronics 23: 995.

37. Bonel L, Vidal J C, Duato P, Castillo J R (2011) Biosensors and Bioelectronics, 26, 3254-3259.

38. Alonso-Lomillo M A, Domínguez-Renedo O, del Torno-de Román L, ArcosMartínez M J (2011) Analytica Chimica Acta, 688, 49-53.

39. Kadara OR, Tothill IE (2004) Analytical and Bioanalytical Chemistry 378:770.

40. Surugiu I, Dey ES, Svitel J, Pirvutoiu S, Danielsson B (2001) The Analyst 126:1633.

41. Currie, L.A. "Detection: International Update, and Some Emerging Di-Lemmas Involving Calibration, the Blank, and Multiple Detection Decisions." Chemometrics and Intelligent Laboratory Systems 37 (1997): 151-181.

42. Volpe G, Compagnoneb D, Draiscia R, Palleschi G (1998) The Analyst 123:1303

43. Badea M, Micheli L, Messia MC, Candigliota T, Marconi E, Mottram T, VelascoGarcia M, Moscone D, Palleschi G (2004) Analytica Chimica Acta 520:141

44. Avramescu A, Noguer T, Magearu V, Marty J-L (2001) Analytica Chimimica Acta 433: 81.

45. Horisberger M, Vauthey M (1984) Histochemistry 80:13. 
Biographies

Meike Heurich, received her $\mathrm{PhD}$ degree in Analytical chemistry from Cranfield University and her research is focused on analytical methods development.

Mohamad Kamal Abdul Kadir, has just completed his PhD degree in biosensors development and is now focussing on food analysis.

Ibtisam E. Tothill $(\mathrm{PhD})$ is a Reader in Analytical Biochemistry and Head of the Advanced Diagnostics and Sensors group at Cranfield Heath, Cranfield University. Her research is focused on development of sensors and diagnostics for health care, food and environmental analysis. 


\section{Figures}

Figure1. Schematic diagram depicting the immunosensor procedure used for ochratoxin A analysis.

Figure 2. Current $(\mu \mathrm{A})$ versus electrochemical potential, $\mathrm{E}[\mathrm{V}]$ which shows the cyclic voltammograms (CV) of $20 \mu \mathrm{TMB}$ solution in $0.1 \mathrm{M} \mathrm{KCl}$ on the screen-printed gold electrode at different scan rates $[v]$. From inner to outer cyclic voltammogram the scan rate is $25 ; 50 ; 75 ; 100 ; 150 ; 200$; and $400 \mathrm{mV} \mathrm{s}^{-1}$ (vs. screen-printed $\mathrm{Ag}$ - $\mathrm{AgCl}$ reference electrode).

Figure 3: Standard curve for the detection of ochratoxin A using indirect ELISA format on a microtiter plate. Standard deviation is depicted as error bars $(n=3)$ and the curve fitted using a 4-parameter fit, linear range of 1-1000 $\mu \mathrm{g} \mathrm{L}^{-1}$ ochratoxin A. The dynamic range from 1-1000 $\mu \mathrm{g}^{-1}$, linear $r^{2}$ value of 0.99 .

Figure 4. Standard curve for the detection of ochratoxin A using the developed passive absorbed gold surface modified immunosensor. (a) chronoamperometry measurement at $-150 \mathrm{mV}$ vs. $\mathrm{Ag} / \mathrm{AgCl}$ for different concentration of ochratoxin $\mathrm{A}(0.001$ to 10,000 $\mu \mathrm{g} \mathrm{L}^{-1}$ ), (b) current $[\mathrm{I}, \mu \mathrm{A}]$ vs. ochratoxin A concentration $\left[\mu \mathrm{g} \mathrm{L}^{-1}\right]$, measurements taken after 150s. Error bar $=$ standard deviation, $n=3$, Coefficient of variation $=6 \%, L O D=$ $0.5 \mu \mathrm{g} \mathrm{L}^{-1}$. The dynamic range is $0.1-10 \mu \mathrm{g} \mathrm{\textrm {L } ^ { - 1 }}$, linear $r^{2}$ value of 0.99 .

Figure 5. Competitive response curve of current $[\mu \mathrm{A}]$ versus ochratoxin A concentration $\left[\mu \mathrm{g} \mathrm{L}^{-1}\right]$ on CMD-modified SPGE. Chronoamperometry measurement $-150 \mathrm{mV}$ vs. $\mathrm{Ag} / \mathrm{AgCl}$, Error bar $=$ standard deviation, $\mathrm{n}=3$, Coefficient of variation $=$ $8 \%$, the $\mathrm{LOD}=0.05 \mu \mathrm{g} \mathrm{L}{ }^{-1}$, the dynamic range is $0.01-100 \mu \mathrm{g} \mathrm{L}$.

Figure 6. \% Competition versus ochratoxin A concentration $\left[\mu \mathrm{g} \mathrm{L}^{-1}\right]$ on CMDmodified SPGE, showing comparison of analysis conducted in buffer samples and spiked wine samples. Wine samples were extracted using immunoaffinity columns and analysed using the sensor. Chronoamperometry measurement $-150 \mathrm{mV}$ vs. $\mathrm{Ag} / \mathrm{AgCl}$, Error bar $=$ standard deviation, $\mathrm{n}=3$. 
Figure 1.

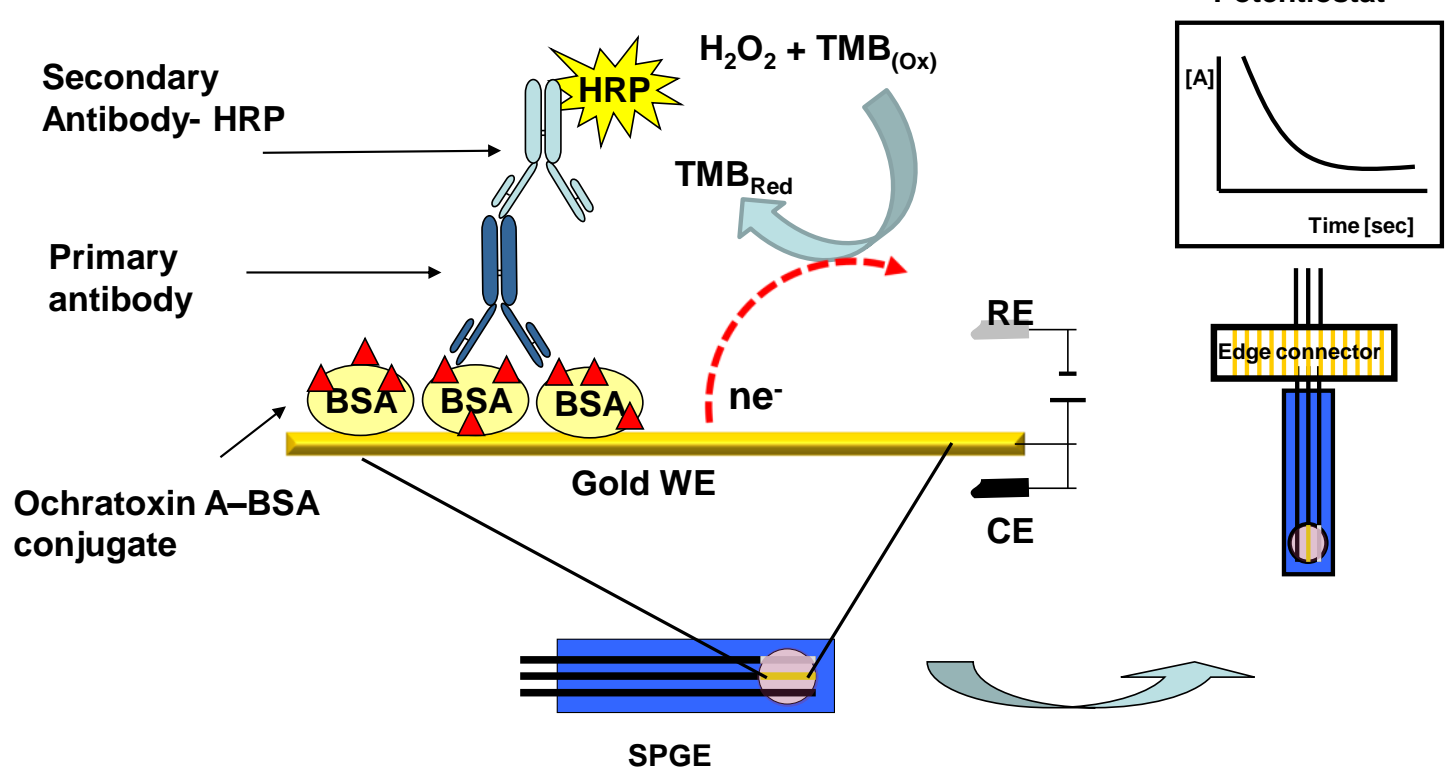


Figure 2.

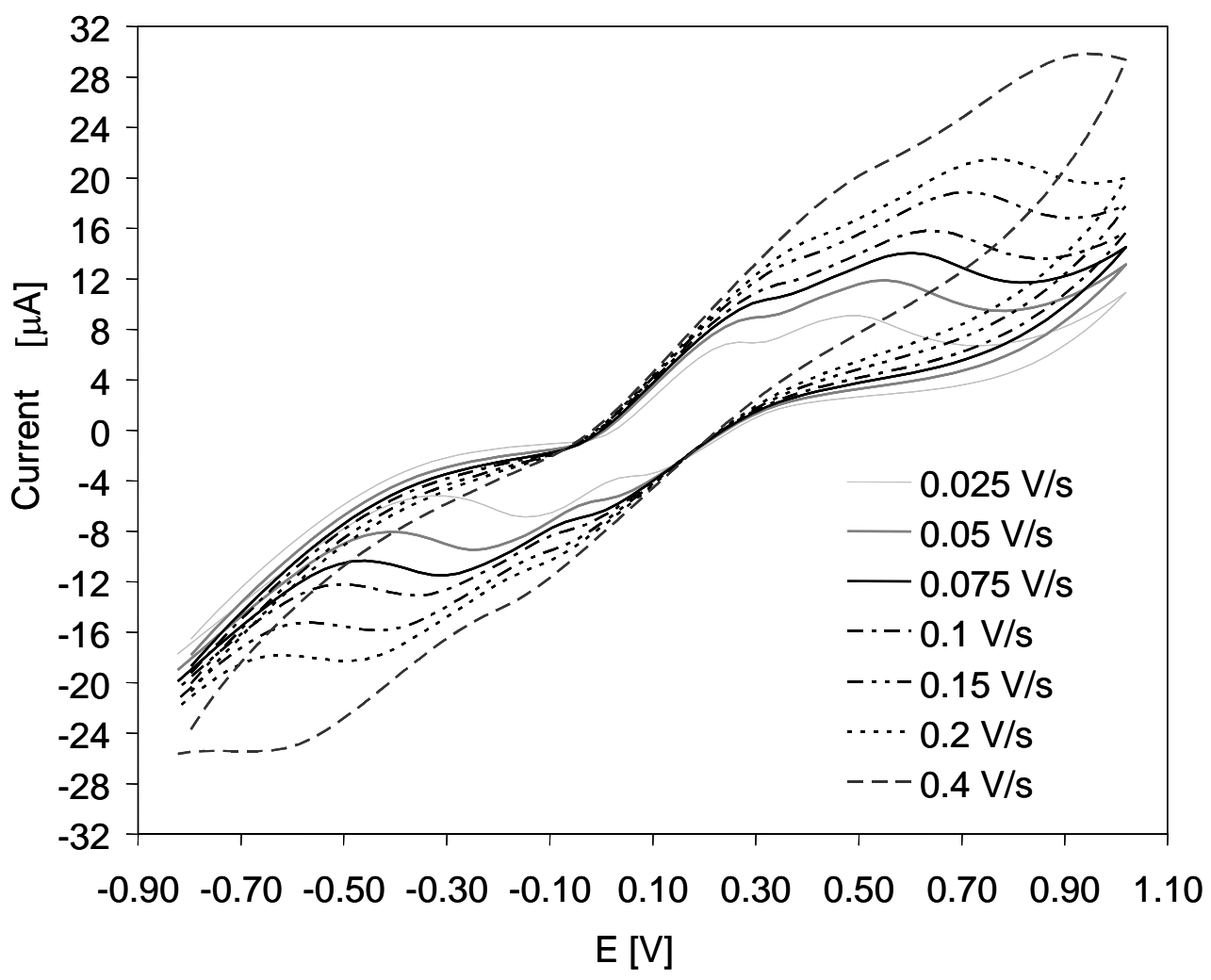


Figure 3.

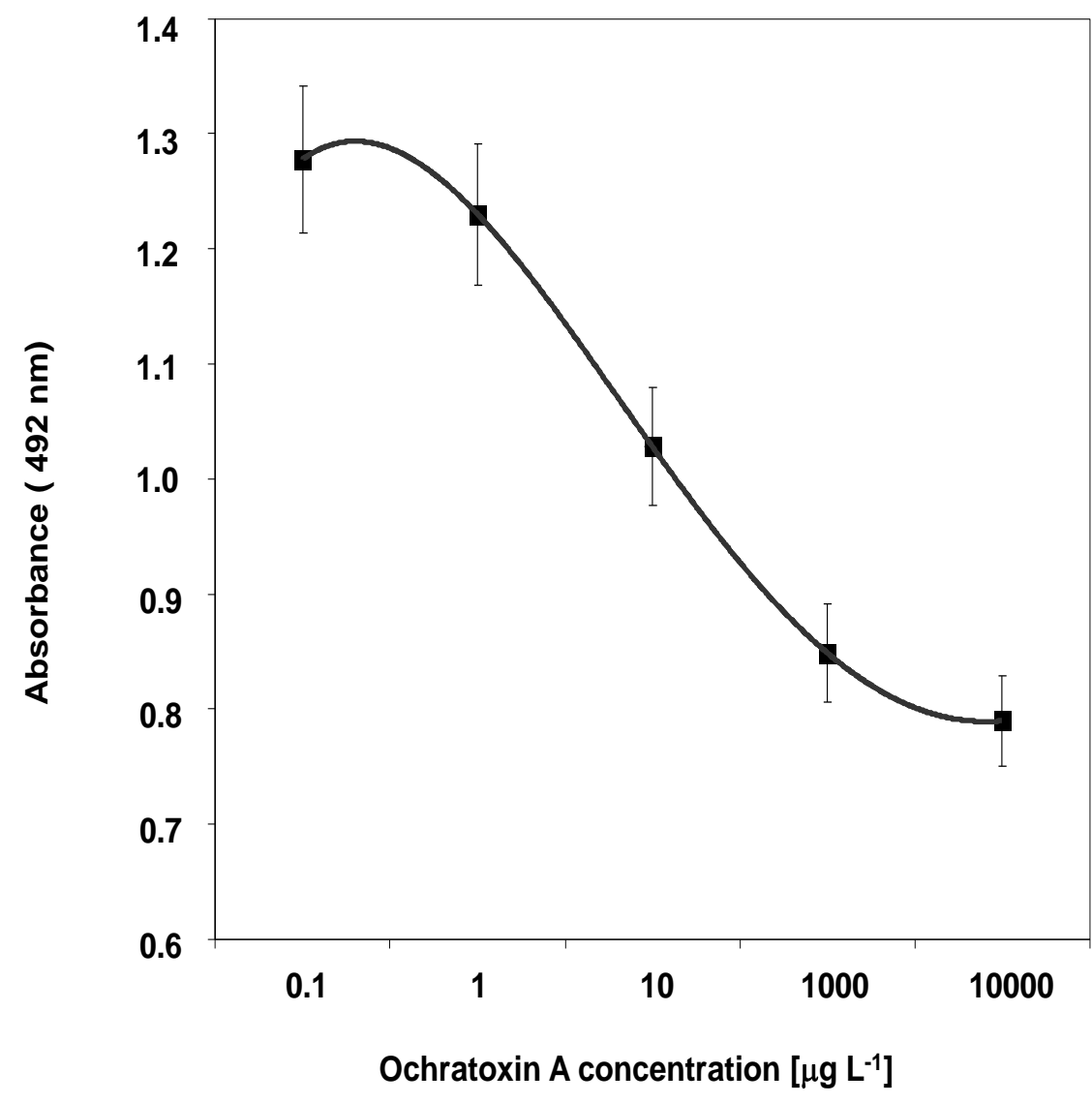


Figure 4.

(a)

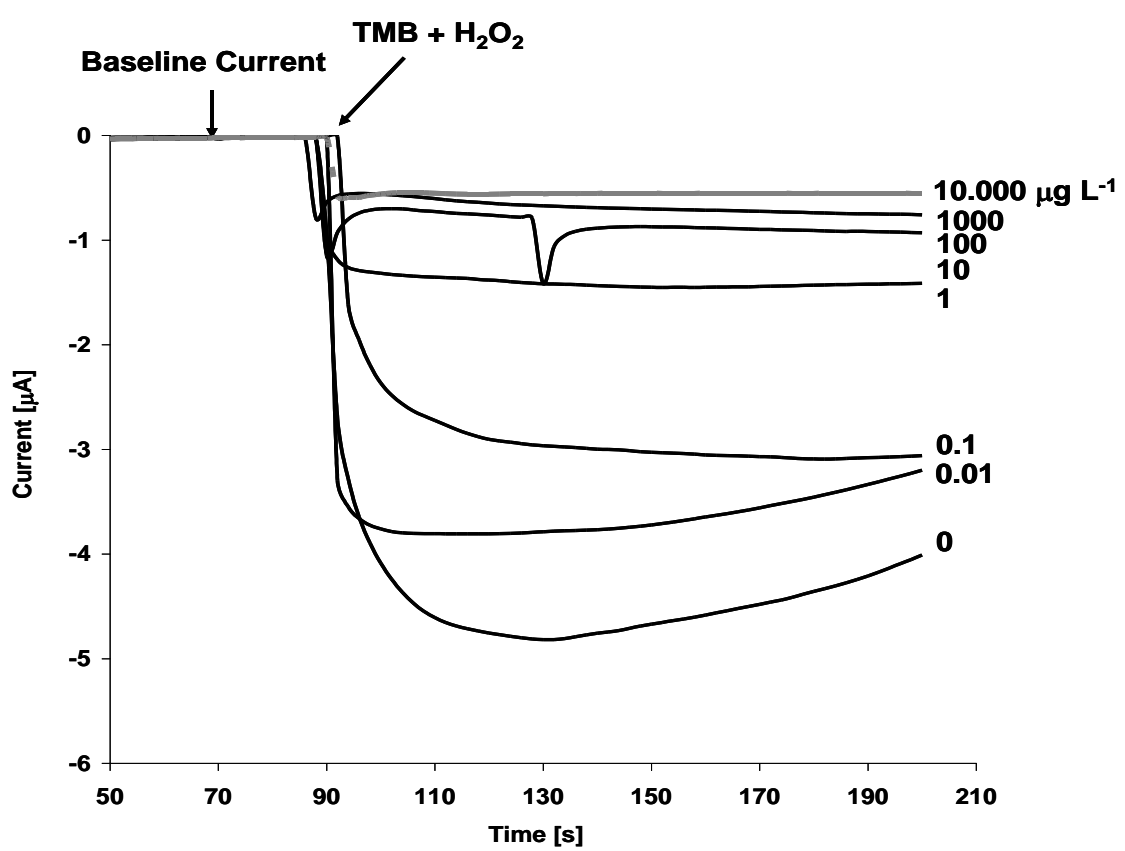

(b)

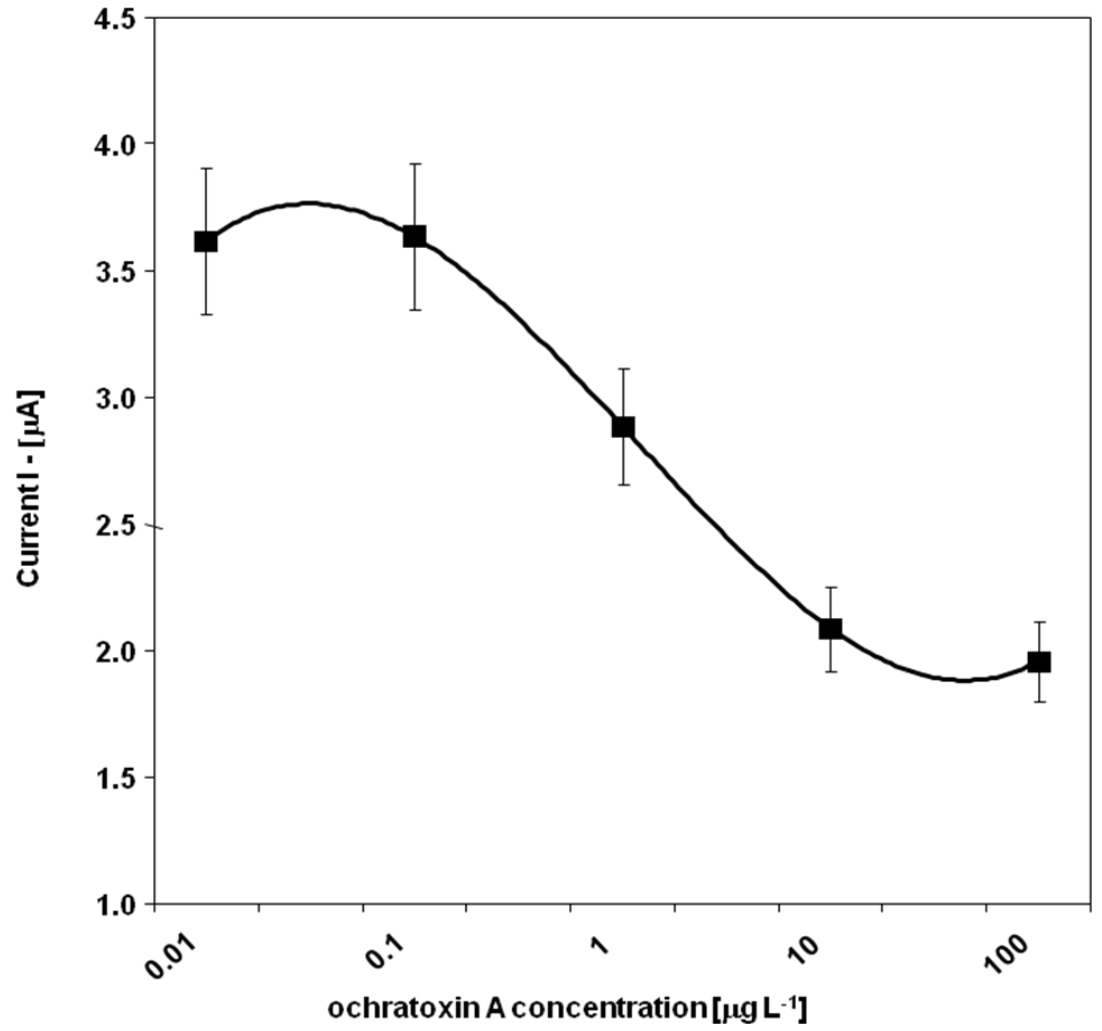


Figure 5.

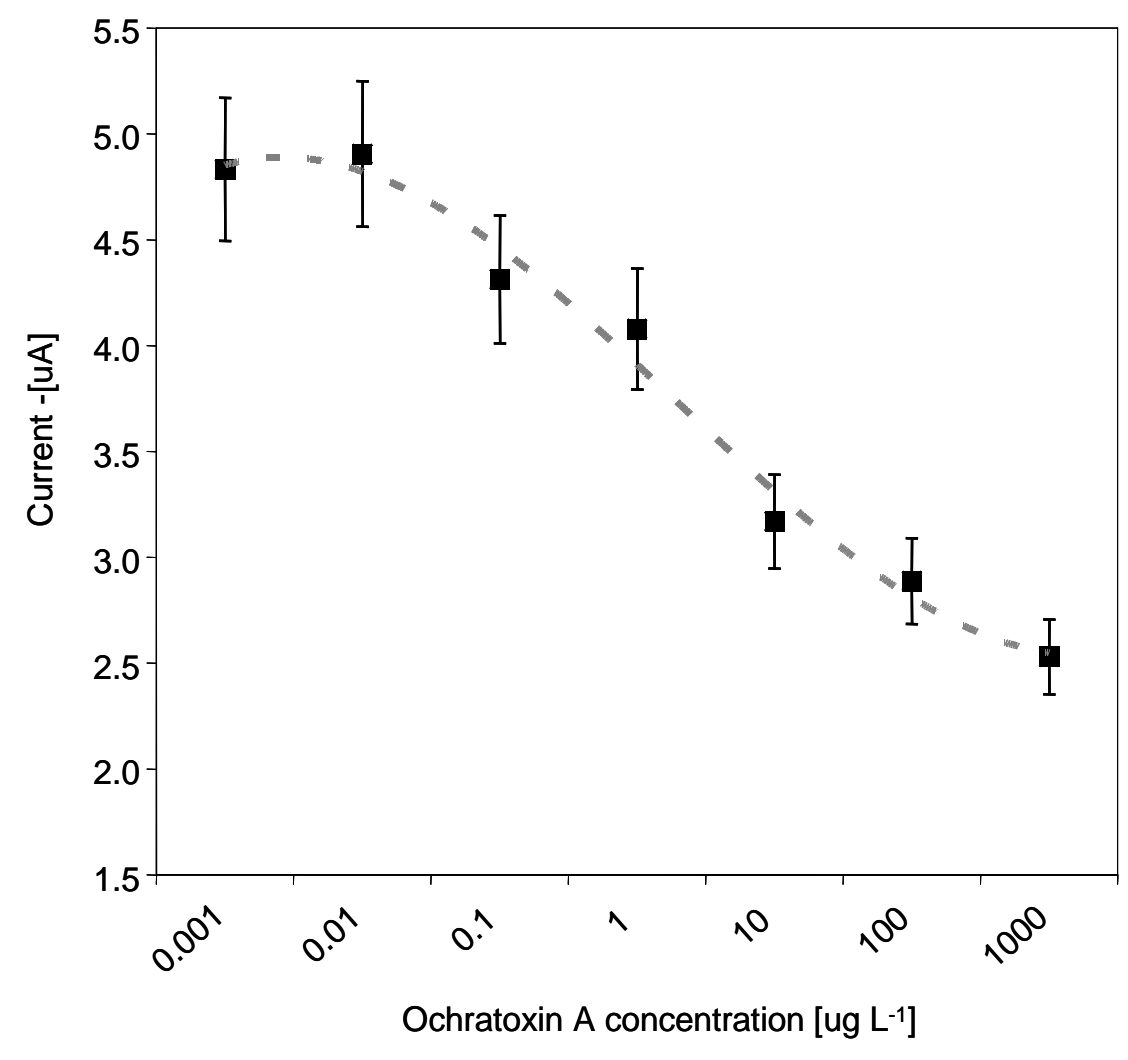


Figure 6.

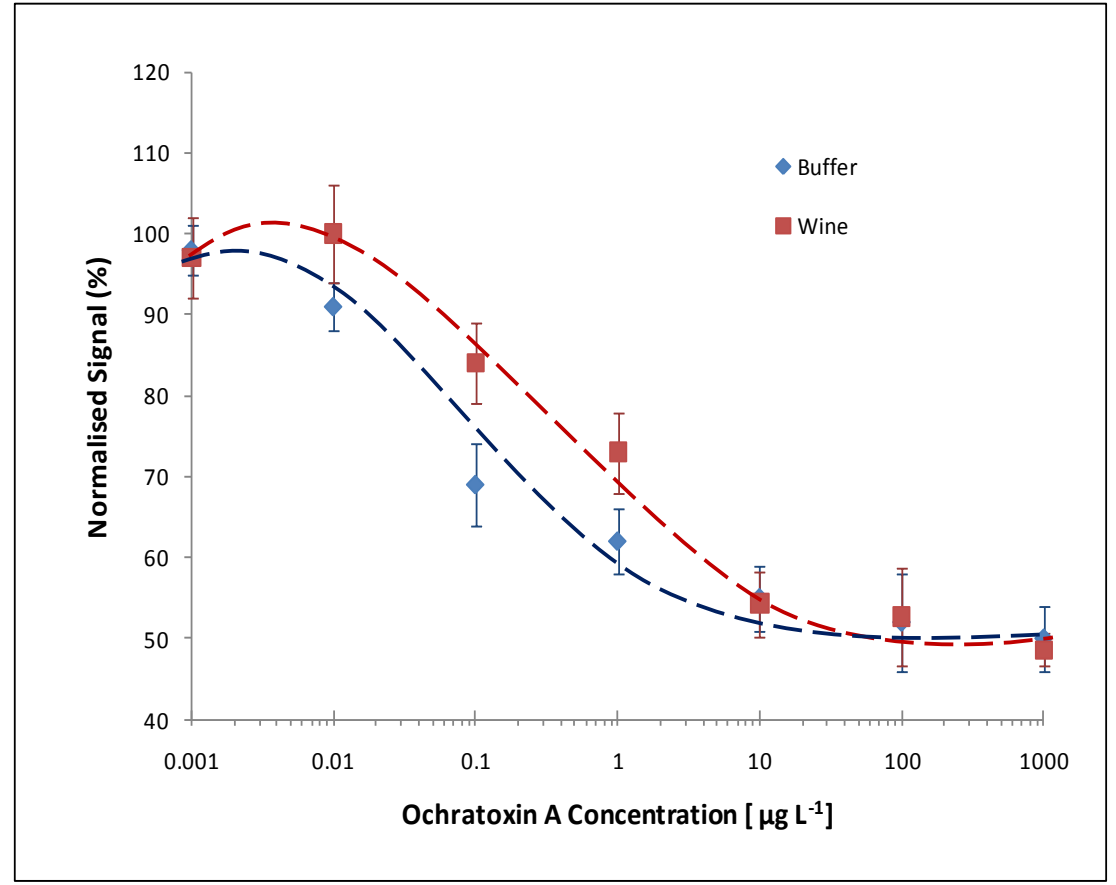

